\section{Espectadores da condição humana em ambientes midiáticos}

[Spectators of human condition in media environments]

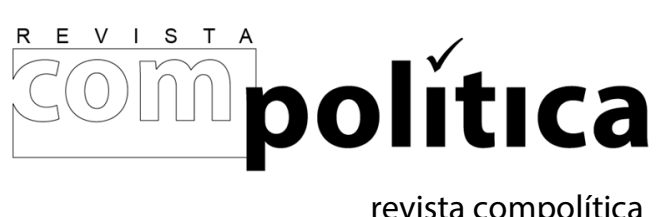

revista compolítica 2019, vol. 9(1)

compolitica.org/revista

ISSN: 2236-4781

DOI: 10.21878/compolitica.2019.9.1.237

O Open Access Journal

Thales Vilela Lelo

Universidade do Estado de Minas Gerais

[Minas Gerais State University]

\begin{abstract}
Resumo
O artigo parte de discussões contemporâneas no campo dos estudos de mídia que problematizam a apatia dos espectadores em face de narrativas que retratam injustiças e tragédias humanitárias. Estas pesquisas identificam que a insensibilidade das audiências estaria também atrelada à desumanização da alteridade que povoa a paisagem midiática. Por meio de uma investigação teórica, pretende-se abordar o tema recuperando expoentes da filosofia política que evidenciam o caráter circunstancial da condição humana e os entraves às ações políticas calcadas exclusivamente em apelos morais. $\mathrm{Na}$ sequência, é proposto um deslocamento conceitual das formas de estruturação das reivindicações em direção à reconfiguração dos regimes de sensibilidade no campo perceptivo do espectador, possibilitando que vidas sistematicamente violadas possam ser enfim percebidas como humanamente cognoscíveis..
\end{abstract}

Palavras-chave: mídia, moralidade, humanidade.

\title{
Abstract
}

The article starts from contemporary discussions in the field of media studies that problematize the apathy of spectators in face of narratives that portray injustices and humanitarian tragedies. These researches identify that the insensitivity from audiences would also be tied to the dehumanization of the otherness that populates the media landscape. Through a theoretical research, the intention is to address the issue by recovering exponents of political philosophy that evidences the circumstantial character of human condition and the obstacles to political actions whose are based exclusively on moral appeals. In the sequence is proposed a theoretical displacement from forms of structuring the claims to reconfiguration of sensibility regimes in the perceptive field of spectator, allowing that systematically violated lives would be finally be perceived as humanly knowable.

Keywords: media, morality, humanity. 


\section{Espectadores da condição humana em ambientes midiáticos}

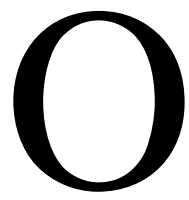

s estudos de mídia contemporâneos, ao menos no Hemisfério Norte, vêm sofrendo uma profunda guinada moral em suas agendas investigativas (Orgad \& Seu, 2014) que os têm conduzido a se enfocarem na apreensão dos mecanismos discursivos que tornam as audiências, ao redor do globo, afeitas ou não aos apelos de uma alteridade distante materializada nas narrativas de tragédias humanitárias. Embora muitos dos autores e autoras identificados com essa senda investigativa - como Luc Boltanski (2004) ou Roger Silverstone (2007) - estejam preocupados em identificar os desafios ligados à construção de um senso de responsabilidade ética entre as audiências e as imagens de corpos sofredores que ocupam as telas de televisores, as páginas dos jornais ou os feeds de notícias em redes sociais, outras incursões se debruçam na tarefa de evidenciar os artifícios empregados pelos media para tornarem os públicos do Ocidente suficientemente impassíveis diante das injustiças que presenciam via relatos sobre grupos de refugiados cruzando desesperadamente as fronteiras de seus países para escaparem da morte em conflitos armados; minorias raciais, étnicas ou de gênero expostas a toda sorte de ofensas, desrespeito e abordagens hostis; ou ainda calamidades naturais que assolam países periféricos e ocasionam as mortes de milhares de pessoas em decorrência das precárias condições de existência as quais estas populações estão submetidas.

É certo que os corpos que povoam essas cenas de "sofrimento à distância", como se convencionou nomear tais circunstâncias de estímulo à reação moral frente às imagens mediadas (Boltanski, 2004; Chouliaraki, 2006), frequentemente são apresentados despidos de seu pertencimento ao gênero humano, que tornaria os espectadores empáticos diante de sua vulnerabilidade compulsória. A razão para essa neutralização do senso de humanidade partilhada é frequentemente localizada no invólucro cultural e imagético que possibilita a experiência do espectador. Este argumento é particularmente recorrente. Susan Moeller (2002), por exemplo, alerta que a torrente de notícias sobre acontecimentos calamitosos que diariamente inundam a mídia instaura uma "fadiga de compaixão" nas audiências algo como uma overdose que colapsa o engajamento moral. Na mesma linha, as teorizações 
complementares de Silverstone (2007) e Marita Sturken (2011) irão discorrer sobre uma "retórica do mal" disseminada na sociedade estadunidense ao ponto de estabelecer uma "cultura do conforto" nas audiências daquele país - audiências essas que assistem calmamente a banalização da tortura quando promovida por militares contra sujeitos rotulados como terroristas.

Parece-nos menos debatido, todavia, esse processo de desumanização da alteridade que torna determinados corpos assimetricamente expostos a condições injustas e indignas sem que suas tragédias sejam gatilhos para uma sensibilização moral do espectador e uma problematização política das desigualdades. Se, como argumenta Jacques Rancière (2010), não há correspondência direta entre o conteúdo político de uma mensagem e sua capacidade de suscitar o julgamento crítico da audiência, então como é possível desnaturalizar o olhar do espectador de modo que ele reconheça a humanidade em sujeitos até então alocados à margem dos regimes morais vigentes?

Por meio de uma excursão teórica a expoentes da filosofia política contemporânea, este artigo pretende investir em uma resolução a esta interrogação. Recuperando argumentos presentes nas obras de autores e autoras que vêm refletindo sobre a alocação diferencial e assimétrica da condição humana (como Achille Mbembe, Adriana Cavarero, Axel Honneth, Rancière e Judith Butler), a primeira seção do texto explicita como estas formulações teóricas não se resumem à detecção crítica das patologias sociais que banalizam as violações sofridas por determinadas formas de vida (apreendidas como menos que humanas). O diagnóstico proposto por estas obras fornece uma conceituação normativa das lutas daqueles que, em tese, demandam reconhecimento de qualidades de valor denegadas pelos demais (no caso, as audiências que se dispõem a presenciar determinadas manifestações de sofrimento sem, com isso, questionarem os marcos desiguais de pertencimento a uma humanidade comum).

As reservas para com teorizações que propõem que o motor de ação nesses contextos de reivindicação é uma exigência de reconhecimento de conteúdo moral são apresentadas no tópico subsequente. O inconveniente destas formulações, como será apontado, é o de circunscrever ao domínio da moralidade formas de desrespeito que negam a própria humanidade dos injustiçados. Por esta razão, uma via alternativa de enfrentamento da 
discussão será delineada na última seção, deslocando o enfoque da moralidade para a transformação dos regimes de percepção sensível dos espectadores via experiências singulares. Concluir-se-á que esta é uma hipótese promissora (a ser explorada em investigações empíricas ulteriores) para compreender o processo de desnaturalização do olhar que possibilita a apreensão de formas de vida até então confinadas às fronteiras da humanidade.

\section{Multiplas faces da inumanidade}

O pensamento radical contemporâneo vem tecendo uma crítica à negatividade inerente ao humano. Em um debate estabelecido entre Cavarero e Butler (2007), as autoras refletem sobre este filão da filosofia política que teria se debruçado na desconstrução da universalidade da condição humana. A afirmação do caráter circunstancial da humanidade serviria tanto à dissolução da ideia de que o humano teria algo próprio à sua existência (uma natureza essencial) bem como à detecção crítica das situações nas quais essa pertença ao gênero humano é, ao mesmo tempo, negada e reivindicada sob as mais variadas feições: jurídica, de inserção na espécie, de obrigação ética, de atribuição de valor moral, de sensibilização dos públicos de narrativas midiáticas, etc.

Nos termos de Cavarero (2007, p. 650), apresentados neste mesmo debate, "é como se a natureza humana fosse uma questão que não tem a ver com o lugar da espécie humana na classificação do mundo dos seres vivos, mas sim com o modo como os humanos desvelam para si mesmos o paradoxo da sua humanidade". A inumanidade - que serve de vetor a uma problematização das violações sofridas por vidas que figuram aquém do gênero humano - é então tratada como uma categoria relacional desvelada em situações comunicativas nas quais determinadas matrizes de sentido são acionadas circunscrevendo os modos de percepção sensível da alteridade.

A desrealização do sofrimento e da precariedade imposta àqueles aos quais é negada a humanidade sob variadas feições é um ponto fulcral aos referidos autores e autoras e que pode iluminar sobremaneira a indagação, anteriormente formulada, sobre as vias não diretivas de sensibilização do espectador em face do "sofrimento à distância", que acomete 
corpos frequentemente apresentados na paisagem midiática como destituídos das características que nos permitiram identificá-los como pertencentes ao gênero humano. No pensamento de Cavarero (2007, p. 652), por exemplo, a inumanidade aparece em primeiro plano "toda vez que a vítima da violência é um ser indefeso, desarmado, ou seja, reduzido à sua pura vulnerabilidade". Isto é, se o humano é, por definição, o exposto enquanto ser vulnerável, então a inumanidade é o umbral da agressão, a sua precariedade constitutiva que "dilacera o corpo enquanto corpo, destruindo-o em sua totalidade simbólica, desfigurando-o" (Cavarero, 2009, p. 26). Mbembe (2011), por sua vez, irá se inspirar na noção de biopoder oriunda da obra de Michel Foucault para evidenciar como a violência colonial em países como a África do Sul operou por meio da racialização e consequente negação de humanidade ao colonizado: "Aos olhos do conquistador, a vida selvagem não é mais que outra forma de vida animal, uma experiência horripilante, algo radicalmente ‘outro' (alien), muito além da imaginação ou da compreensão” (Mbembe, 2011: 40)².

Já a identificação do logos (a capacidade de falar e entabular discussões) como recurso de atribuição e negação da humanidade é central a Rancière (1996), que se reporta ao pensamento grego clássico para afirmar que o elemento próprio ao dissenso político não é o confronto de opiniões de seres previamente identificados como detentores do logos, mas sim a reivindicação de um logos por aqueles que são socialmente apreendidos como dispondo apenas de uma phoné (uma voz limitada expressar sentimentos de prazer e dor):

\footnotetext{
Quem quer que esteja na presença de um animal que possua a habilidade para articular a linguagem e seu poder de demonstração, sabe que está lidando com um humano e, portanto, um animal político. A única dificuldade prática reside em saber qual signo pode ser reconhecido, ou seja, como se pode ter certeza que um animal humano fazendo barulho a sua frente está atualmente articulando um discurso em vez de meramente expressar um estado de ser? (Rancière, 2010, p. 37-38)
}

Segundo o autor, o elemento próprio ao dissenso político não é o confronto de opiniões entre os detentores do logos, mas sim sobre a imputação dessa capacidade aos emissores de sons. Quando alguém não é reconhecido como ser político, são percebidos, da sua boca, ruídos inaptos a configurar um discurso. Esse operador sensível da desigualdade teria propiciado a exclusão, ao longo da história, de sujeitos julgados como meros animais 
fônicos (mulheres, operários, negros) confinados ao espaço doméstico no qual seus ruídos de necessidade poderiam ser vocalizados sem perturbar a racionalidade das deliberações promovidas pelos supostos detentores da razão. Quaisquer que fossem os objetos que designassem como matéria visível de litígio político seriam sumariamente desconsiderados. Qualquer linguagem que empregassem para exporem o dano que sofrem não seria percebida como uma linguagem comum. Ser desconsiderado como ser humano falante é, segundo Rancière (1996, p. 42), ser conformado a uma ordem policial na qual "a ordem do visível e do dizível (...) faz com que essa atividade seja visível e outra não o seja, que essa palavra seja entendida como discurso e outra como ruído". Em síntese: ser percebido como um ser despido daquilo que o torna essencialmente humano.

Em Precarious Life e, posteriormente, em Frames of War, Butler se aproxima mais detidamente da paisagem midiática ao questionar, por exemplo, o descompasso entre a comoção pública e o sentimento de luto ocasionado pela morte de milhares de estadunidenses vítimas dos atentados de 11 de setembro de 2001 (devidamente singularizados nos atos simbólicos de rememoração do ataque) e a apatia diante dos também milhares de palestinos mortos pelas forças de Israel sob apoio estadunidense (aos quais nem mesmo sabemos os nomes). Para a autora, a experiência singular com a alteridade (seja ela mediada ou não) é regulada pela violência normativa que reduz certas formas de vida ao domínio do ininteligível, inaudível e invivível, enquanto outras são enquadradas em sua particular vulnerabilidade, o que possibilita a emanação de um senso de responsabilidade pela dignidade destas quando ameaçadas injustamente (Butler \& Athaniasou, 2013).

A violência da desrealização das mortes, segundo Butler (2006), é o que converte algumas perdas em inauditas. Não há injúria ou negação imputável em uma vida indisponível à lamentação. Mas, para que algumas existências sejam qualificadas como menos que humanas, é preciso que elas estejam marcadas às margens das normas que delineiam a esfera do aparecer. "Uma figura viva fora das normas da vida não somente se converte no problema de gerir a normatividade, mas parece ser isso mesmo o que a normatividade está obrigada a reproduzir: está viva, mas não é uma vida" (Butler, 2010, p. 22). Prossegue a autora: "se alguém é 'framed', sobre a ação dessa pessoa se constrói um 'quadro' tal que o 
estatuto de culpabilidade dela se converte na conclusão inevitável do espectador" (Butler, 2010, p. 23).

Não obstante a premência de explorar esse diagnóstico negativo da denegação de humanidade a determinadas formas de vida (expostas cotidianamente nos media sem necessariamente instigar reações morais do espectador em consequência), para prosseguir pelo horizonte delineado por este trabalho, será necessário dar um passo além no ímpeto de compreender as possíveis estratégias empregadas por estes corpos desumanizados para evidenciarem, politicamente e coletivamente, como suas existências foram arbitrariamente impedidas de serem reconhecidas como propriamente humanas.

Ancorado no projeto da Teoria Crítica Alemã e sob determinante influência da filosofia do reconhecimento de Hegel, Honneth (2003), herdeiro de uma geração que remonta a Theodor Adorno e Max Horkheimer, e inclui Jürgen Habermas, é um dos autores mais dedicados a esse empreendimento. Em sua teoria do reconhecimento - ao menos na versão sistematizada na obra Luta por reconhecimento (2003), o autor elabora uma crítica da realização patológica ou incompleta do social que, no capitalismo neoliberal, acenaria para a destituição das condições de autorrealização dos seres humanos e de construção da identidade. Honneth argumenta que os movimentos sociais mais frequentemente surgem de reações a experiências negativas, que podem se materializar como formas de desrespeito ao tocar a integridade corporal dos viventes contra sua vontade, ou ainda minar as fontes de autorrespeito daqueles que não se veem como detentores de determinados direitos ou dignos de serem valorizados em igual status como parceiros de interação ${ }^{3}$. As injustiças se materializariam então em formas de desrespeito capazes de ferir as pessoas em uma compreensão positiva de si mesmas - adquirida de maneira intersubjetiva ao longo da vida.

Por esta razão, nos termos de Honneth, quando os sujeitos conseguem articular uma demanda pelo reconhecimento indevidamente negado sob as condições existentes, o que transcorre é o acionamento de um processo que arranca os engajados da situação de paralisia e de sofrimento inaudito em que se encontravam, demandando, na esteira, uma revisão das normas sociais que agora são publicamente percebidas como injustas. O elo que Honneth estabelece entre o padecimento e a ação política tem no horizonte uma ampliação das formas de reconhecimento existentes, e por essa razão possui um conteúdo, 
sobretudo, moral (ou seja, o reconhecimento é uma forma de perceber no outro uma qualidade de valor adequada aos propósitos, desejos e necessidades dos demais). Mas uma questão parece não ficar muito bem resolvida nessa linha de raciocínio estabelecida por Honneth: como é possível reconhecer qualidades de valor denegadas a seres que nem mesmo são apreendidos como carentes por integridade pessoal? Se a ação de reconhecimento possui um conteúdo moral determinado pelo valor de outras pessoas, qual é a moralidade que nos liga àqueles que não percebemos como existências que gozam desse predicado?

Essas indagações ecoam na problemática condutora desse texto: diante de corpos os quais determinados espectadores não identificam como propriamente humanos, não basta que as vozes que emanam de seus lábios ecoem nas narrativas para que sejam de fato ouvidas acionando um gatilho de sensibilidade moral, até então retido. A suspeita que ronda imagens que se inclinam a serem lidas como disparadoras de ações de reconhecimento é crescente - e tem como antecedente próximo as controvérsias sobre a eficácia das campanhas de agências humanitárias que visavam engajar o espectador para determinadas causas (Boltanski, 2000). Na paisagem midiática contemporânea (onde pululam gravações amadoras capturadas por smartphones), as audiências diariamente se defrontam com situações nas quais se autorizam a descredenciar o teor político de uma reivindicação por motivações das mais variadas, indo da desqualificação do interlocutor à desconsideração das demandas que ele vocaliza - ou ainda contestando a veracidade das imagens quando se tratam de cenas de nítida injustiça ${ }^{4}$. Assim sendo, antes que lutas por reconhecimento (no sentido moral do termo), no horizonte atual não estaríamos também discorrendo sobre lutas voltadas à transposição de uma percepção de humanidade denegada?

\section{Do reconhecimento à cognoscibilidade}

A interrogação precedente nos obriga a esmiuçar uma faceta complementar dos estudos em filosofia política apresentados na seção anterior no que diz respeito ao diagnóstico crítico da inumanidade patente nas expressões relacionais da condição humana: um potencial emancipatório supostamente capaz de decompor os mecanismos que atuam na produção circunstancial dessa forma de violência. 
Por esta razão, faz-se premente evidenciar como esta profunda negatividade no enfrentamento com a modernidade convive com uma possibilidade de libertação imanente. Ou seja, como se delineia a passagem do juízo sobre a ausência de humanidade imposta a determinadas formas de vida à sua apreensão enquanto existências indevidamente tolhidas de figurar nos marcos da condição humana.

No esteio da teoria do reconhecimento concebida por Honneth (2003), como já fora antecipado, são as experiências de desrespeito - em sua capacidade de dilacerar as fontes de autorrealização que constituem os sujeitos humanos - que podem se transmutar em impulso motivacional de uma luta para obter o reconhecimento denegado sob as condições existentes. Mas, para que as experiências pessoais de degradação moral possam se configurar em uma luta no sentido coletivo do termo, é necessário que tais injustiças sejam percebidas intersubjetivamente como atinentes a um grupo maior. E isto só ocorre, nos adverte o filósofo alemão, quando o entorno político e cultural é uma fonte de motivação para resistência dos concernidos, lhes permitindo visualizar, no reconhecimento antecipado da comunidade de comunicação forjada na luta, uma demanda por justiça que extrapola aquela indevidamente disponível na sociedade. Assim sendo, "o engajamento nas ações políticas possui para os envolvidos também a função direta de arrancá-los da situação paralisante do rebaixamento passivamente tolerado e de lhes proporcionar, por conseguinte, uma autorrelação nova e positiva" (Honneth, 2003, p. 259) e, para além, uma ampliação progressiva das relações de reconhecimento.

A despeito da valiosa contribuição de Honneth na confecção do elo que conduz do sofrimento de desumanização à ação política (e ao potencial de reconfiguração das normas vigentes), cabe problematizar a capacidade de o reconhecimento servir como operador satisfatório em uma busca pela aquisição das condições mais elementares de autorrealização persistentemente violadas. Butler, em discussão tecida com Athena Athaniasou (2013), alerta que as normas de reconhecimento envolvem uma profunda dependência de termos os quais o sujeito não escolhe para emergir como um ser inteligível e, desta feita, implicam em consequências materiais para aqueles que são ou não interpelados diretamente por elas, operando uma violência adicional nesses que permanecem irreconhecíveis nos marcos de atribuição da humanidade. Na sequência, Athaniasou conclui o argumento: 
O reconhecimento é um aparato que discursivamente produz sujeitos como humanos (ou inumanos, sub-humanos, menos que humanos) por termos normativos e disciplinares tais como gênero, sexualidade, raça e classe. Quando uma vida que não figura como normativamente humana é violada, essa violação permanece irreconhecível, mal reconhecida ou reconhecida de modo injurioso, através de termos que permitem a desrealização da violência (2013, p. 90).

Por conseguinte, para Butler (2010) é fundamental ter em conta as dificuldades que ascendem ao primeiro plano quando o enfoque são formas de vida, até então, não contabilizadas como propriamente humanas, pois não há laço moral a nos ligar àqueles que são julgados como existências desrealizadas. Segundo a autora, quando um sujeito toma a palavra ou se desloca no espaço público, se assume em geral que ele é alguém que tem liberdade de falar e de se mover. Mas é preciso tomar nota de que esses direitos nem sempre são garantidos. Em sua perspectiva, se o corpo é menos uma entidade estável do que uma existência fugaz dependente das condições relacionais e ambientais que garantem sua permanência, sua vulnerabilidade imanente indica uma condição de ampla interdependência.

O deslocamento acenado por esse prisma argumentativo se avizinha das preocupações mais imediatas a este artigo quando nos deparamos com suas consequências em plano empírico. No que concerne à cobertura midiática de conflitos armados em regiões nas quais se avolumam os crimes contra civis (como na Síria ou na Palestina), é nítido o fato de que tais acontecimentos insidiosos só serão tratados como crimes pelos noticiários se esses reconhecerem os alvos das atrocidades como civis no sentido pleno do termo (e, portanto, vidas vulneráveis, carentes por proteção). $\mathrm{O}$ assassinato de seres não contabilizados como perdas efetivas recebe a alcunha já corrente nos media de "dano colateral" (Butler, 2015).

Outrossim, o assassinato sistemático de jovens negros no Brasil, corriqueiramente identificados pela polícia como "tipos ideais" de criminosos, permite que uma virtual culpabilidade emerja dadas as condições apropriadas e sem que qualquer delito tenha de fato ocorrido (Ramos \& Musumeci, 2004). Tal prática de incriminação prévia - que prescinde de um processo de acusação, inquérito formal ou mesmo a existência real de um crime - torna determinados corpos alvos potenciais do Estado e vidas indisponíveis à 
lamentação em caso de extermínio. Nos media modernos, tais mortes ora são reduzidas a um quadro estatístico (e por assim dizer, naturalizadas), ora são enquadradas em esquemas normativos que não convidam ao reconhecimento dos desrespeitos sofridos - porque tais desrespeitos são julgados incontornáveis à luz do propósito maior de garantir as condições ambientais de sobrevivência daqueles percebidos como seres humanos vulneráveis.

No ímpeto de indicar uma via de enfrentamento a esta intrincada problemática que ronda as políticas de reconhecimento, Butler desloca o eixo de teorização das fontes morais de motivação à ação em direção aos regimes de percepção das formas de vida. Elabora um conceito de "apreensão" como modo de conhecimento ligado à percepção sem que esteja diretamente atrelado ao reconhecimento para, em seguida, asseverar que uma vida deve primariamente ser inteligível como humana para, só então, resultar reconhecível (Butler, 2010). Indica, por fim, a "cognoscibilidade" como uma condição geral que precede ao reconhecimento. Para Butler, ao tomarmos nota de uma existência humana não reconhecida como tal, podemos convertê-la na base para uma crítica das normas correntes. "O que ocorre quando um quadro rompe consigo mesmo é que uma realidade dada por certa é posta em tela de julgamento, deixando expostos os planos instrumentalizadores da autoridade que tentava controlar dito quadro" (Butler, 2010, p. 28). Incorre desse descentramento das normas uma oportunidade para que os seres abjetos nos termos vigentes se “autorreconheçam”, como defende Athaniasou no diálogo com Butler (2013, p. 65): “o discurso normativo do abjeto e da exceção adjudicada é performativamente reformulado nessa auto poética excepcional" que redistribui os quadros que definem o self reconhecível.

Em certo sentido, o método de irrupção da cena política na obra de Rancière - calcado no deslocamento dos regimes de distribuição do sensível - resguarda elementos comuns com esta caracterização. Como supracitado, para o autor, a fronteira entre os animais políticos, possessores da logos, e os reles emissores de ruídos, é naturalizada em uma suposta separação primordial de formas de (in)humanidade: de um lado, os aptos à compreensão dos problemas; do outro, os destinados ao perpétuo cumprimento das ordens. Todavia, conforme Rancière (1996), o que se pressupõe na sugestão de que alguns só conhecem a linguagem das ordens não é que o processo comunicativo possa ser livre de desentendimentos no intercâmbio entre os que decretam e os que acatam, mas sim que os dominados devam crer, nas entrelinhas da ordem, no lugar desigual que se espera que 
assumam. Ora, esse refinado potencial de compreensão é o mesmo daqueles que autodenominam genuinamente capazes. Se não há disparidades tão essenciais entre um e outro é porque, afirma Rancière (1996), a ordem social é calcada em uma contingência última. Desta percepção enuncia-se uma cisão na, até então, harmônica regulação dos corpos em comunidade.

O dano, para o filósofo francês (Rancière, 1996), nada mais é do que a exposição da contradição entre dois mundos alojados em um só. Em uma camada, está um universo que organiza os sujeitos conforme suas supostas disposições fundamentais à compreensão; em outra, o incontornável fato da igualdade das capacidades que sustenta a ficção desigual. O que a ação dos supostamente carentes de logos reivindica não é uma igualdade futura ou o direito a tomar parte em uma lógica que os segrega. Em ato, eles encenam a igualdade que lhes é negada, expondo a arbitrariedade da ordem que preceituava seus modos de ser, dizer e pensar. Desidentificam-se com os lugares prescritos e promovem uma reconfiguração do campo da experiência. No que o filósofo francês entende por política, espaço privilegiado há para a metamorfose dos regimes de apreensão sensível que, até então, naturalizavam os lugares ocupados pelos sujeitos no corpo social. Trata-se, sobretudo, de "introduzir novos sujeitos e objetos, em tornar visível o que não era visto e fazer ouvir como falantes os que eram percebidos como animais barulhentos" (Rancière, 2012, p. 26).

Tal relevo excepcional atribuído por Butler e Rancière aos deslocamentos operados no campo perceptivo - entendido aqui como gatilho para redistribuição dos sistemas de alocação desigual da humanidade - sustenta-se na premissa de que não há reivindicação por reconhecimento de valor moral a ser atendida a quem não é julgado como propriamente humano. Para estes autores, há um componente estesiológico que atua como força motriz desse processo de apreensão de existências cognoscíveis: se os domínios da percepção são delineados também por perspectivas interditas à visualização e excluídas do campo sensorial, é preciso levar em conta que estes impedimentos deixam impressões em nossas sensibilidades primárias uma vez que atravessam nossas existências como sensualidades exteriores constitutivas - dispostas para além de qualquer deliberação ou escolha (pois atinentes a uma receptividade fundamental forjada desde a infância). Em outras palavras, as normas sociais nos endereçam por trilhas as quais não somos totalmente conscientes e, por isso, 
vários vetores de poder, incluindo normas sociais e modos de discriminação entre vidas lamentáveis, registram-se no nível da sensibilidade primária, tomando posse apesar de nós, nos animando, e formando uma dimensão quase involuntária de nossas vidas somáticas (Butler \& Athaniasou, 2013, p. 96).

Butler (2010) chega mesmo a reivindicar que o papel crítico da cultura visual contemporânea é o de problematizar os quadros de apreensão sensível que produzem normas desumanizadoras - limitando o que pode ser percebido e quais existências serão julgadas descartáveis. A alusão ao enquadre fotográfico é elucidativa do tipo de argumento proposto pela autora: embora a câmera esteja fora do quadro, ao mesmo tempo, ela compõe a imagem como seu exterior constitutivo, delimitando um horizonte que exibe e descarta aspectos da cena. E, assim como o campo perceptivo, a cena enquadrada também está de partida circunscrita pelas perspectivas que nunca se deixam ver ou são proibidas de aparecer por estarem excluídas do campo visual. Estes frágeis pontos de vista desconsiderados só estão disponíveis à percepção como vestígios do que poderia ter sido, assim como os corpos que mesmo violados estão indisponíveis à lamentação, pois apreendidos como indícios de uma humanidade a qual não lhes pertence.

Reivindicar a percepção sensível dessa humanidade denegada (tencionando a composição do enquadramento) é então uma tarefa que precede ao reconhecimento do valor moral de humanos injustamente tolhidos de suas possibilidades de autorrealização. Não obstante, na paisagem midiática hodierna, esses corpos abjetos são representados nos limiares de uma distância inapropriada no contato com o espectador, como formulara Silverstone (2007): ora são demasiadamente excêntricos e pertencentes a mundos longínquos, de forma que entre nós e eles não parece subsistir qualquer traço de humanidade comum; ora estão tão próximos que o sofrimento abismal que os vitima passa a ser entendido como um componente intransponível de sua existência. Mas, no mais das vezes, essas duas fronteiras parecem se cruzar, a exemplo de refugiados de países periféricos expostos ao trabalho escravo e às condições insalubres de moradia e alimentação na Europa e nos Estados Unidos, ou ainda as populações brutalmente desumanizadas em decorrência de padrões opressivos de inteligibilidade cultural (como grupos LGBT em diversos países ou mesmo pessoas em situação de rua e moradores de periferia). 
Em face desta torrente de imagens, que corriqueiramente reforçam padrões coercitivos de apreensão sensível do mundo e de seus habitantes, inquietações anteriormente formuladas adquirem novo tom de urgência: como os deslocamentos no campo sensorial provocam uma reorientação nos regimes de cognosbilidade humana, desnaturalizando o olhar do espectador do enquadre que lhe era habitual? E, parafraseando Rancière (2012, p. 26), como é possível "introduzir novos sujeitos e objetos (...) tornar visível o que não era visto e fazer ouvir como falantes os que eram percebidos como animais barulhentos" em um ambiente midiático em que são imperativas as lutas sociais voltadas à transcendência de códigos de percepção que denegam humanidade a certas formas de vida?

\section{Sensibilidades vinculantes, experiências singulares}

Investir em uma dimensão estesiológica como disparadora do processo de reconfiguração dos quadros de apreensão relacional da cognoscibilidade humana, através da senda desvelada no tópico precedente, conduz-nos a refletir sobre uma sinestesia primária que conforma os modos de regulação dos dados sensoriais disponíveis à percepção. Ou ainda, um sensus communis que nos torna inicialmente partilhantes, na perspectiva de Herman Parret (1993).

No itinerário que conduz ao encontro com os fundamentos patêmicos e sensoriais da sociabilidade, Parret se aparta da primazia da racionalidade comunicativa - cara à geração da Teoria Crítica que teve Habermas como principal expoente -, em favor do contato sinestésico responsável pela configuração de uma sensibilidade comum que precede às faculdades discursivas. Nos termos do autor, "é a categoria estética do sensus communis que serve como valorização legitimadora de cada prática intersubjetiva na vida cotidiana" (Parret, 1993, p. 159). Logo, pensar o tecido social pelo prisma das sensorialidades partilhadas nos leva a concluir que "o sentimento de estar com os outros ou o sensus communis precede o sentimento de valor" (Parret, 1993, p. 154). À vista disso, os horizontes axiológicos e a ordem predicativa dos juízos constituem os estratos superiores e reflexivos dos fenômenos comunicativos (Picado, 2013). 
O que a reflexão de Butler acrescenta a essa linha de raciocínio é a hipótese de que o liame originário dessa matriz sensível (que forja a experiência do mundo e das formas de vida que o habitam) opera uma regulação dos elementos disponíveis à percepção, dificultando que sejamos afetados pelas sensibilidades não enquadradas em sua tessitura. $\mathrm{O}$ que então nos possibilita perceber esses dados excedentes (não circunscritos em certo campo habitual de experimentação do mundo) é um deslocamento nas modalidades vigentes de filtragem do sensível.

Yves Citton (2009) desenvolve esse argumento, em uma leitura expansiva da obra de Rancière, ao propor que sensibilidades partilhadas consistem na contabilização de certos estados de coisas e no descarte de outros. Há sempre mais dados acessíveis à apreensão sensorial do que aqueles que podem ser efetivamente registrados no campo da experiência. Por essa razão, revela-se imperativo que transcorra um processo de filtragem. Certos dados são então notados como mais relevantes pelo nosso aparato sensório (determinando nossa conduta futura) enquanto outros são apagados pelo caminho, compondo o excesso desta estesia vinculante. Ou seja, a circunscrição do campo da experiência decorre de marcos hegemônicos que delineiam quais estratos do mundo e das vidas que nele habitam são cognoscíveis à nossa mirada.

O que ocorre então para que seres até então desconsiderados nas modalidades de seleção vigentes - indignos de adentrarem no filtro das sensibilidades pertinentes - possam transbordar a superfície do quadro que os aparta da percepção enquanto humanos? Butler (2010) já antecipara, como anteriormente levantado, que toda norma é delineada por seu excesso constitutivo, e que por vezes esse excedente invade o quadro perturbando as formas habituais de experimentação do mundo, alterando, na esteira, os sistemas de filtragem dos elementos sensíveis.

Mas como tais regimes desviantes das sensibilidades hegemônicas despontam na experiência do espectador? Vimos que a sensibilização e o engajamento dos públicos em face de determinadas violências vertidas em imagens não são derivados da carga política intencional presente na mensagem que as encadeia em uma narrativa midiática. Mesmo a vocalização de injustiças sofridas por grupos que aspiram reconhecimento intersubjetivo presume que eles sejam percebidos como humanos dotados de valores morais 
infundadamente denegados. Quando não há humanidade comum a vincular o espectador às vidas que povoam seus entornos midiáticos a suspeita sobre as imagens visualizadas ocupa o espaço daquilo que deveria ser uma reação de indignação e empatia diante da alteridade.

Diante do exposto, constata-se que não há como propor uma fórmula que oriente o espectador a reconhecer diretivamente a humanidade em existências legadas às margens dos quadros normativos de apreensão sensível - revolucionado as formas de percepção do mundo e solucionando os dilemas daqueles que lutam para serem percebidos como propriamente humanos. Isto posto, resta a convicção de que, quando esses processos de desnaturalização do olhar ocorrem, não são propiciados por experiências rotineiras ou dispersas, pois essas se restringem a reprodução dos códigos de filtragem dos dados sensoriais voltados à resolução de problemas práticos e à compreensão irrefletida do mundo.

As sensibilidades emergentes capazes de deslocar os padrões de apreensão relacional da cognoscibilidade humana sobrevêm em experiências singulares, no sentido proposto por John Dewey (2010), dotadas de qualidade ímpar e pontuadas por um fluxo que caminha rumo a sua consecução pelo espectador. Estas experiências, capazes de reconfigurarem as confianças e certezas que o público tinha sobre o mundo e os humanos que a ele pertencem, são embaladas por um ingrediente emotivo que "seleciona o que é congruente e pinta com suas cores o que é escolhido, com isso conferindo uma unidade qualitativa a materiais externamente díspares e dessemelhantes" (Dewey, 2010, p. 120), tragando o espectador para seu curso de afetação de tal modo que ele não mais pode ignorar as interdições que configuravam seu campo perceptivo. E, se a emoção advinda dessas experiências intensas é oriunda da relação do espectador com os seres que paulatinamente vão se tornando cognoscíveis ante seus sentidos, isto se deve ao fato de que há uma fase intelectiva a conferir significado à experiência, permitindo um equilíbrio entre a comoção propiciada do contato possível com uma humanidade emergente e a reconfiguração ativa e reflexiva das formas naturalizadas de desumanizá-la.

Resta uma última indagação diante da proposição de que são experiências singulares (dotadas de ingredientes afetivos e intelectivos) as forças motrizes da reconfiguração dos 
regimes sensoriais que tornam cognoscíveis formas de vida desumanizadas: o que é sensivelmente percebido pelo espectador em uma existência que reivindica ser apreendida como humana? A hipótese aqui aventada é a de que a percepção mobilizada nesses encontros com uma alteridade emergente resguarda em seu cerne uma atenção ao olhar (em sentido amplo) desse ser humano que mira em direção ao espectador. Este outro que podia ser encarado ostensivamente sem que propiciasse o afluxo de uma humanidade partilhada com aquele que o defrontava agora se revela capaz de devolver a mirada que lhe é dirigida.

Os estudos de mídia mencionados na introdução deste texto frequentemente discorrem sobre uma "distância apropriada" a ser estabelecida em face da representação do outro (Chouliaraki, 2006; Silverstone, 2007; Sturken, 2011). Essa distância nada mais é que a medida justa para que a alteridade possa devolver o olhar que lhe é destinado pelo espectador. Perceber um corpo alvejado pela ação desmesuradamente ostensiva de forças policias em repressão a um protesto ou ainda pela violência ideologicamente motivada de grupos extremistas como um humano injustamente assassinado exige que, diante da narrativa de sua tragédia, possamos lamentar por essa vida perdida ao sermos afetados por sua mirada agonizante.

Não obstante o fato antropológico da interdependência humana (Butler \& Athaniasou, 2013), em certos regimes hegemônicos de partilha das sensibilidades, essa mútua implicação é negada em benefício à afirmação de independência do olhar, como se o sujeito pudesse se constituir em autonomia daqueles que por eles são vislumbrados como formas abjetas de existência. À vista disto, nas experiências singulares com essa alteridade até então abstraída de cognoscibilidade humana instaura-se não só uma vívida oportunidade de desarticulação das modalidades dominantes de filtragem dos dados sensoriais, mas, sobretudo, de promoção de uma abertura sensível ao outro.

\section{Considerações finais}

“Tornar sensível”, nos assevera Georges Didi-Huberman, corresponde a "tornar acessível aos sentidos, e tornar acessível inclusive ao que nossos sentidos, assim como nossas inteligências, nem sempre conseguem perceber como algo que 'tem sentido': algo que 
somente aparece como falha no sentido, indício ou sintoma" (2014, p. 100). Ao longo deste artigo, partimos de uma problemática cara a uma seara dos estudos de mídia que tomou para si a tarefa de compreender os entraves ao engajamento crítico do espectador diante de imagens de corpos vitimados por catástrofes e injustiças de toda sorte diariamente visualizadas em telas de variados formatos. Destacamos que há um desafio adicional quando os corpos retratados são desumanizados de maneira tal que os vínculos morais que poderiam ser estabelecidos entre eles e os públicos de suas tragédias são cindidos.

Voltamo-nos então às situações em que grupos sistematicamente injustiçados clamam pelo reconhecimento de suas qualidades de valor denegadas no ímpeto de vislumbrar as táticas adotadas pelos sujeitos que compõem essas coletividades para obter o respeito que lhes foi negado. Mas, mais uma vez, nos defrontamos com o impasse de que este tipo de ação política presume a existência de um sujeito que, a despeito da precariedade de sua condição, é intersubjetivamente percebido como humano e, portanto, capaz de vocalizar em forma de demanda moral sua queixa.

Se ser espectador do mundo é um traço de nossa existência que extravasa o contato pontual com narrativas áudio-verbo-visuais, como nos alerta Marie-José Mondzain (2010), deslocamos então nosso eixo argumentativo em direção aos códigos que conformam o campo perceptivo desse espectador - sustentando que este é circunscrito por perspectivas interditas à apreensão (local onde residem as formas de vida desumanizadas que não são consideradas aptas a demandar o engajamento moral de seus interlocutores). Defendemos que a desnaturalização do olhar do espectador - que possibilita que certos corpos sejam enfim concebidos como existências humanas - exige uma reconfiguração dos regimes sensoriais hegemônicos, reconfiguração esta que transcorre preferivelmente em experiências singulares, dotadas tanto de qualidades emotivas quanto intelectivas. Consideramos, por fim, que nestas circunstâncias de deslocamento das sensorialidades dominantes o fio condutor da experiência é a apreensão do olhar de uma alteridade anteriormente julgada incapaz de devolver a mirada que lhe era dirigida (pois tolhida de alguns caracteres elementares que lhe permitiriam a apreensão como humana).

Evidentemente que não se trata da imputação de valor normativo ou teleológico ao domínio estesiológico (já que não há garantias de que a cada experiência singular se desdobrará, 
consecutivamente, uma atribuição de valor moral), e muito menos da rotunda asserção de que os seres previamente não enquadrados nos regimes sensoriais e afetivos da percepção estão decisivamente tolhidos de qualquer cognoscibilidade como humanos. É mesmo possível que em alguns aspectos tais existências sejam contempladas como igualmente humanas, mas, sob outros (possivelmente os mais decisivos), suas vozes estejam confinadas ao ruído e seu olhar destinado a um consumo desprovido de empatia pelas iniquidades que sofrem. Enquanto esforço eminentemente teórico de resolução de um impasse presente em filões do pensamento político contemporâneo, este trabalho acena para um horizonte a ser futuramente explorado em investigações empíricas dedicadas a compreender os desafios implicados nas lutas de grupos sistematicamente injustiçados (que reivindicam, nos mais diversos dispositivos midiáticos, uma humanidade comum com os seus espectadores). Tais estudos podem inclusive apontar para imperfeições no encaminhamento sugerido, limitado por seu caráter especulativo.

Por conseguinte, também não se busca aqui apresentar uma virtuosidade política imanente à experiência singular no sentido pragmatista do termo. É evidente que nem todas as experiências intensas oferecem a oportunidade de reorientação dos padrões de apreensão sensível da alteridade. Mas, ao mesmo tempo, considera-se fundamental ter em mente que, em circunstâncias nas quais os espectadores presenciam, apáticos, o acúmulo de violações dirigidas contra seres que mal são reconhecidos como humanos, são estas experiências os únicos acontecimentos capazes de provocar um distúrbio nos modos corriqueiros de apreensão do mundo. Por fim, a aposta central deste trabalho (que pode vir a subsidiar estudos que tenham a paisagem midiática como referência de análise) é que nessas circunstâncias, por mais efêmeras que possam ser, a percepção se vê deslocada e o ambiente impregnado pelos traços do encontro entre sujeitos que agora se percebem reciprocamente humanos.

\footnotetext{
Notas

1 Uma versão preliminar do presente trabalho foi apresentada ao Grupo de Trabalho "Comunicação e Experiência Estética", no XXVI Encontro Anual da Compós. Agradeço aos membros do grupo pelas valiosas sugestões feitas na ocasião, devidamente incorporadas nesta nova versão.

${ }^{2}$ Todas as citações em idiomas estrangeiros foram traduzidas pelo autor.
} 
${ }^{3}$ Os três estágios de desrespeito concebidos pelo projeto crítico de Honneth (2003) correspondem a uma morte psíquica, social e uma vexação dos sujeitos que tangenciam as soleiras da condição humana.

${ }^{4}$ A exemplo do caso de uma jovem no Rio de Janeiro que, em 2016, foi violentada por mais de 30 homens que distribuíram imagens do estupro em redes sociais. A despeito da barbaridade do ato, à época em que as cenas circularam, sua veracidade não só foi contestada, bem como a própria condição de vítima da jovem motivou litígio na opinião pública.

\section{Referências}

BOLTANSKI, Luc. The Legitimacy of Humanitarian Actions and their Media Representation: The Case of France. Ethical Perspectives, v.7, p.3-16, 2000.

BOLTANSKI, Luc. Distant Suffering: morality, media and politics. Cambridge: Cambridge University Press, 2004.

BUTLER, Judith. Vida precaria: el poder del duelo y la violencia. Buenos Aires: Paidós, 2006.

BUTLER, Judith. Marcos de guerra: las vidas lloradas. Barcelona: Paidós, 2010.

BUTLER, Judith; ATHANIASOU, Athena. Dispossession: the performative in the political. Cambridge: Polity Press, 2013.

BUTLER, Judith. Human shields. London Review of International Law, v.0, n.0, p.1-21, 2015.

CAVARERO, Adriana. Horrorismo: nombrando la violencia contemporánea. Barcelona: Anthropos Editorial, 2009.

CAVARERO, Adriana; BUTLER, Judith. Condição humana contra "natureza". Estudos Feministas, v.15, n.3, p.647-662, 2007.

CHOULIARAKI, Lilie. The spectatorship of suffering. London: Sage, 2006.

CITTON, Yves. Political Agency and the Ambivalence of the Sensible. In: ROCKHIL, G.; WATTS, P. (Orgs.). Jacques Rancière: History, Politics, Aesthetics. Durham and London: Duke University Press, p.140-157, 2009.

DEWEY, John. Arte como experiência. São Paulo: Martins Fontes, 2010.

DIDI-HUBERMAN, Georges. Volver sensible/hacer sensible. In: GONZÁLEZ, C. e RODRIGUÉZ, F. (Orgs.) ¿Qué es un pueblo? Buenos Aires: Eterna Cadencia Editora, p.69-100, 2014.

HONNETH, Axel. Luta por reconhecimento: a gramática moral dos conflitos sociais. São Paulo: Editora 34, 2003.

MBEMBE, Achille. Necropolítica seguido de sobre el gobierno privado indirecto. Santa Cruz de Tenerife: Editorial Melusina, 2011.

MOELLER, Susan. Compassion fatigue: how the media sell disease, famine, war and death. New York: Routledge, 2002. 
MONDZAIN, Marie-José. What does seeing an image mean? Journal of Visual Culture, v.9, p.307-315, 2010.

ORGAD, Shani; SEU, Irene. The mediation of humanitarianism: toward a research framework. Communication, Culture \& Critique, v.7, p.6-36, 2014.

PARRET, Herman. The Aesthetics of Communication: pragmatics and beyond. Boston: Springer Science+Business Media Dordrecht, 1993.

PICADO, Benjamin. Discursividades estéticas nas teorias da comunicação. Questões Transversais, v.1, p.41-49, 2013.

RAMOS, Sílvia; MUSUMECI, Leonarda. Elemento suspeito: Abordagem policial e discriminação na cidade do Rio de Janeiro. Boletim Segurança e Cidadania, v.3, n.8, p.1-16, 2004.

RANCIÈRE, Jacques. O desentendimento: política e filosofia. São Paulo: Editora 34, 1996.

RANCIÈRE, Jacques. Dissensus: on politics and aesthetics. London: Continuum International Publishing Group, 2010.

RANCIÈRE, Jacques. El malestar en la estética. Buenos Aires: Capital Intelectual, 2012.

SILVERSTONE, Roger. Media and Morality: On the Rise of the Mediapolis. Cambridge: Polity, 2007.

STURKEN, Marita. Comfort, irony, and trivialization: The mediation of torture. International Journal of Cultural Studies, v.14, p.1-18, 2011.

\section{O autor}

Thales Vilela Lelo é Doutor em Ciências Sociais pela Universidade Estadual de Campinas (Unicamp) e Professor da Universidade do Estado de Minas Gerais (UEMG) - Unidade Divinópolis. thales.lelo@gmail.com 